\title{
ETIKA KERJA ISLAM SEBAGAI FAKTOR DETERMINAN TERHADAP KINERJA KARYAWAN PT. X DI KOTA BANDUNG
}

\author{
Fauzan Akbar Widiansyah \\ Program Studi Manajemen, Fakultas Pendidikan Ekonomi dan Bisnis, \\ Universitas Pendidikan Indonesia, Bandung, Indonesia \\ fauzanakbar92@gmail.com
}

\begin{abstract}
The main of this research is to resolve decreasing employee performance of Manufaturing Department at PT. X arround 3 years beginning of time, by using Islamic Work Ethics approach as independent variable. This research method used descriptive and verification method with 126 employees in the manufacturing department of PT. X as a population of with the number of respondents only 61 employees. The analysis technique used is Pearson product moment correlation coefficient and simple linear regression analysis. Then to test the research hypothesis, $t$-test is used to determine the significance level of the correlation coefficient between the two variables studied. The results showed that the Islamic Work Ethics and Employee Performance were in the middle category, and the calculation results of the correlation coefficient is 0.521, the mean is Islamic Work Ethic had a middle impact of Employee Performance.
\end{abstract}

Keywords: employee performance; islamic work ethics

\begin{abstract}
Abstrak
Dilaksanakannya bertujuan untuk mengatasi permasalahan kinerja karyawan departemen manufaktur PT. X yang mengalami penurunan selama tiga tahun waktu berjalan dengan menggunakan pendekatan Etika Kerja Islam sebagai variabel independen. Metode penelitian yang digunakan adalah metode deskriptif dan verifikatif dengan populasi 126 karyawan departemen manufaktur PT. X dengan jumlah responden berjumlah 61 karyawan. Teknik analisis yang digunakan adalah koefisien korelasi pearson product moment dan analisis regresi linier sederhana. Kemudian untuk menguji hipotesis penelitian, digunakan uji-t untuk mengetahui tingkat signifikansi koefisien korelasi antar kedua variabel yang diteliti. Hasil penelitian menunjukkan bahwa Etika Kerja Islam dan Kinerja Karyawan berada pada kategori sedang, dengan hasil perhitungan koefisien korelasi sebesar 0,521 dengan pengaruh sedang.
\end{abstract}

Kata kunci : etika kerja islam; kinerja karyawan

Corresponding author : Email : fauzanakbar92@gmail.com

History of article : Received: Juli 2019, Revised : September 2019, Published: November 2019 


\section{PENDAHULUAN}

Kinerja karyawan di dalam suatu perusahaan merupakan parameter dari keberhasilan perusahaan tersebut dalam mewujudkan visinya. Borman \& Motowidlo, dalam Sonnentag, Volmer \& Spychala (2008 : 427) menjelaskan secara definitif bahwa kinerja adalah konsep multi-dimensi yang menjabarkan aspekaspek perilaku individu dan outcome yang dihasilkannya selama bekerja. Berdasarkan pernyataan tersebut, terlihat bahwa kinerja bukan merupakan konsep tunggal, akan tetapi konsep multi-dimensi yang di dalamnya menjelaskan tentang aspek- aspek perilaku individu dan outcome yang dihasilkan individu tersebut dalam jangka waktu tertentu. Dan visi perusahaan tentu dapat tercapai salah satunya dengan mangacu kepada outcome kinerja yang dihasilkan oleh masingmasing karyawannya.

Kinerja maksimal yang dikeluarkan oleh setiap individu, tentunya akan berdampak kepada produktivitas kerja sehingga membuahkan berbagai macam keuntungan bagi perusahaan. Selain menekankan perhatian kepada kinerja, sebuah perusahaan memerlukan kepekaan terhadap kebutuhan dan tantangan sosial yang terdapat di sekitar lingkungan bisnisnya. Setiap perusahaan akan bergerak dalam bidangnya masingmasing sesuai dengan potensi yang berkembang di lingkungan tersebut. Berkaitan dengan potensi yang berkembang di lingkungan bisnis tertentu, potensi industri fashion Muslim kini semakin berkembang dan semakin diminati oleh banyak kalangan, khususnya masyarakat Indonesia. Dengan melihat potensi perkembangan populasi umat Muslim di Indonesia, membuat industri fashion Muslim menjadi salah satu pilihan bisnis yang cukup menjanjikan. Populasi umat Muslim di Indonesia merupakan populasi terbanyak di dunia yang ditunjukkan dengan angka 202,867 juta jiwa, berada satu tingkat di atas India yang berada pada posisi kedua dengan populasi
160,945 juta jiwa (Pew Research Center : 2017).

Berdasarkan dengan data bahwa Indonesia merupakan negara dengan populasi umat Islam terbanyak di seluruh dunia, membuat bisnis yang bergerak dalam sektor syari'ah menjadi pilihan yang sangat menjanjikan. Salah satu bisnis yang menjadi perhatian masyarakat Indonesia adalah bisnis busana Muslim, dengan salah satu penggagas utama berdirinya bisnis busana muslim, yaitu PT. $X$. Sebagai perusahaan yang bergerak dalam industri fashion muslim, PT. X menitikberatkan penciptaan produk bernuansa fashion Muslim yang berkualitas dan unggul dibandingkan dengan produk lainnya. Produk dapat tercipta bila komponen utama sebagai kreator produk tersebut bekerja secara optimal. Di dalam perusahaan yang bergerak dalam bidang industri, departemen yang bertugas menjalankan segala macam aktivitas produksi adalah departemen manufaktur.

Berbicara tentang kualitas produk yang diciptakan oleh departemen manufaktur PT. X, tentu berkaitan pula optimalisasi kinerja yang perlu dimiliki setiap insan departemen tersebut. Fenomena yang terjadi di PT. X yang dapat menghambat aktivitas bisnis korporasi adalah penurunan kinerja karyawan, terlebih karyawan departemen manufaktur. Bila kinerja karyawan departemen manufaktur menurun, tentu akan menjadi efek domino kepada setiap proses bisnis yang berjalan di PT. X. Berikut pada Gammbar 1, dijelaskan hasil penilaian kinerja karyawan PT. X Periode 2016 s.d. 2018.

Berdasarkan data hasil penilaian kinerja pada Gambar 1, terlihat bahwa kinerja yang di hasilkan oleh karyawan departemen manufaktur PT.X mengalami penurunan. Dimana pada tahun 2016, angka penilaian berada pada angka 83,40 , kemudian mengalami penurunan di tahun 2017 menjadi 82,60, dan kembali menurun di tahun selanjutnya yaitu tahun 2018 
menjadi 82,00. Tentunya fenomena ini tidak dapat dibiarkan terus terjadi, karena dapat menjadi sebuah ganjalan bagi korporasi untuk melangkah lebih jauh kedepannya. PT. X perlu melakukan evaluasi terkait penurunan kinerja karyawan departemen manufaktur selama tiga tahun tersebut, agar proses produksi dapat berjalan dengan maksimal, yang akan berdampak kepada produktivitas karyawan yang dapat memudahkan segala macam aktivitas bisnis lainnya.

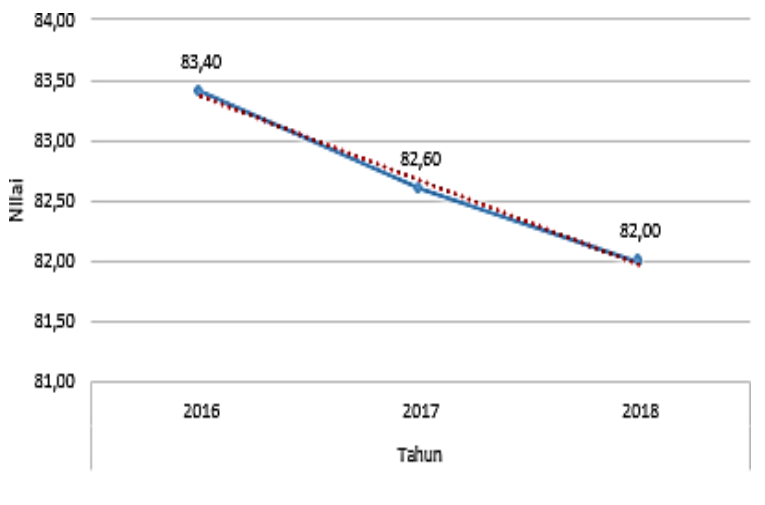

Sumber : Data Sekundsr HRD PT. X Head Office (data diolah kombali)

Gambar 1

Penilaian Kerja Karyawan Departemen

Manufaktur Periode 2016 s.d. 2018

Dalam upaya mengatasi permasalahan kinerja karyawan di dalam perusahaan, terdapat berbagai macam metode yang dapat digunakan untuk menyelesaikannya. Dari beberapa metode yang dapat digunakan untuk menyelesaikan permasalahan kinerja karyawan di dalam perusahaan, salah satu metode yang dapat digunakan adalah dengan mengedepankan aspek etika kerja. Secara lebih spesifik, PT. X memiliki budaya kerja yang kental dengan nuansa Islami, yang dengannya tentu budaya kerja dengan nuansa Islami dapat menjadi salah satu nilai tambah bagi perusahaan di karenakan mengedepankan aspek agama dalam menjalani aktivitas pekerjaan. Berkaitan dengan budaya kerja PT. X yang kental dengan budaya kerja Islami, dan penekanan aspek Etika Kerja, maka penelitian yang hendak dilaksanakan dengan mengedepankan aspek etika kerja sesuai dengan budaya kerja islami yang dimiliki perusahaan dikenal dengan istilah etika kerja islam.

Etika Kerja Islam, menurut Yaseen dkk. dalam Ali (2015 : 288) adalah sebuah orientasi yang menyiratkan kerja sebagai kebajikan dalam memenuhi kebutuhankebutuhan seseorang yang dapat membangun keseimbangan dalam kehidupan pribadi dan sosial seseorang, yang bersumber dari Al-Qur'an dan Sunnah Nabi Muhammad Shallaallaahu 'Alaihi Wasallam. Dengan demikian, dapat diketahui bahwa Etika Kerja Islam merupakan seperangkat nilai dan kepercayaan dalam aspek pekerjaan yang berpedoman kepada Al-Qur'an dan Hadits Nabi Shallallaahu 'Alaihi Wasallam yang dapat membuahkan kebajikan dan membangun keseimbangan dalam kehidupan seseorang.

Dengan mengacu kepada fenomena penurunan kinerja karyawan Departemen Manufaktur PT. X kota Bandung, perlu di rumuskan suatu formulasi yang dapat mengatasi permasalahan tersebut. Penelitian ini mencoba mengurai permasalahan penurunan Kinerja Karyawan Departemen Manufaktur PT. X menggunakan metode etika kerja islam.

Dengan serangkaian fenomena penurunan kinerja karyawan Departemen Manufaktur di PT. X, peneliti mendiagnosa bahwa salah satu solusi untuk mengatasi permasalahan penurunan kinerja yang terjadi pada PT. X adalah dengan menerapkan metode etika kerja Islam. Hal itu sesuai dengan hasil penelitian Ali dan Owaihan dalam Hendrayadi (2018 : 185) yang menjelaskan bahwa etika kerja Islam dapat berkontribusi positif terhadap kinerja dan kesejahteraan organisasi. Adapun dalam penelitian ini terdapat tiga capaian utama, yaitu mengetahui gambaran tingkat Etika Kerja Islam pada karyawan Departemen Manufaktur PT. X, kemudian mengetahui gambaran tingkat kinerja karyawan Departemen Manufaktur PT. X, dan yang 
terakhir adalah untuk mengetahui pengaruh Etika Kerja Islam terhadap Kinerja Karyawan Departemen Manufaktur PT. X.

\section{KAJIAN PUSTAKA Kinerja}

Kinerja menurut Borman \& Motowidlo, dalam Sonnentag, Volmer \& Spychala (2008 : 427) adalah konsep multi-dimensi yang menjabarkan aspekaspek perilaku individu dan outcome yang dihasilkannya selama bekerja.Definisi kinerja di atas merupakan penjabaran terkait konsep multi-dimensi kinerja yang menjelaskan tentang aspek- aspek optimalisasi kinerja yang berasal dari perilaku individu yang berimplikasi kepada outcome yang dihasilkannya.

Berdasarkan teori kinerja di atas, kinerja karyawan memiliki dimensi yang dapat dijadikan sebagai acuan dalam proses penilaian kinerja. Dimensi-dimensi tersebut terdiri atas task performance, contextual performance, dan adaptive performance. (Borman \& Motowidlo, dalam Sonnentag, Volmer \& Spychala (2008 : 428 - 430). Task Performance merupakan kontribusi karyawan terhadap organisasi berupa perilaku dan tindakan yang sesuai dengan deskripsi pekerjaan yang telah di tetapkan oleh perusahaan. Contektual Performance merupakan kontribusi karyawan yang tidak secara langsung terlibat dalam fungsi kegiatan inti organisasi, melainkan kontribusi karyawan berupa aspek psikologis dan aspek sosial yang terdapat di dalam diri karyawan yang dapat mendukung pekerjaannya Adaptive Performance merupakan kontribusi karyawan dalam rangka beradaptasi dengan situasi dinamis yang terdapat di dalam perusahaan.

\section{Etika Kerja Islam}

Etika Kerja Islam, menurut Yaseen dkk. dalam Ali (2015 : 288) adalah sebuah orientasi yang menyiratkan kerja sebagai kebajikan dalam memenuhi kebutuhankebutuhan seseorang yang dapat membangun keseimbangan dalam kehidupan pribadi dan sosial seseorang, yang bersumber dari Al-Qur'an dan Sunnah Nabi Muhammad Shallaallaahu 'Alaihi Wasallam. Untuk dapat mengukur variabel Etika Kerja Islam, terdapat beberapa dimensi Etika Kerja Islam, salah satunya yang digunakan dalam penelitian ini adalah dimensi yang dirumuskan oleh Yaseen dkk., dalam Ali (2015 : 917) yang terbagi ke dalam empat dimensi, yaitu :

\section{Perceived Work as Worship}

Merupakan sikap ketundukan kepada segala perintah Allah Subhanahu Wa Ta'ala, yang dapat menyebabkan setiap aktivitas (dalam hal ini bekerja) menjadi sebuah kebaikan, dan hal ini dapat bernilai ibadah. Sehingga pada prinsipnya, segala bentuk kegiatan dalam Islam adalah semata-mat untuktunduk melaksanakannya sebagai wujud ibadah kepada Subhanahu Wa Ta'ala.

\section{Effort}

Disebut juga sebagai upaya produktif yang ditunjukkan dengan bekerja keras dan ketekunan yang perlu dimiliki setiap insan guna melayani kebutuhan pribadi dan sosial.

\section{Cooperation (Bekerja sama)}

Merupakan kemampuan karyawan untuk bekerja sama dengan karyawan lainnya yang mencapai satu tujuan akhir. Dalam hal bekerja sama ini, Al-Qur'an menjelaskan dalam Surat AlMaidah : 2, “...Dan tolong-menolonglah kamu dalam (mengerjakan) kebajikan dan taqwa, dan jangan tolong-menolong dalam berbuat dosa dan permusuhan..."

\section{Moral Responsibility (Tanggung Jawab Moral)}

Merupakan tanggung jawab moral yang perlu dimiliki setiap insan agar dapat memberikan manfaat kepada orang lain. Karena Islam memerintahkan setiap insan untuk bekerja keras dan bertanggung jawab terhadap lingkungan sekitarnya. 


\section{METODOLOGI PENELITIAN}

Penelitian ini menggunakan desain kausal dengan teknik pengumpulan data secara kuantitatif melalui metode deskriptif dan verifikatif. Sampel dalam penelitian ini diambil dengan pendekatan probability sampling melalui teknik proportionate random sampling yang digunakan ketika populasi memiliki anggota/unsur yang tidak homogen yang kemudian sampel diambil secara acak dari anggota populasi secara proporsional. Jumlah sampel dalam penelitian ini sebanyak 61 orang karyawan departemen manufaktur PT. X.

\section{HASIL DAN PEMBAHASAN}

Analisis Korelasi

Analisis korelasi sederhana digunakan untuk mengetahui tingkat keeratan hubungan antar variabel independen dengan variabel dependen. Hasil analisis korelasi dapat di lihat pada Tabel 2 berikut. Suatu variabel dikatakan memiliki korelasi apabila memiliki tingkat signifikansi $<0,05$. Bila dilihat dari tabel di atas, tingkat signifikansi kedua variabel adalah sebesar 0,00. Maka dapat di simpulkan bahwa terdapat hubungan antara variabel independen, yaitu Etika Kerja Islam dengan variabel dependen, yaitu Kinerja Karyawan dengan interpretasi $\mathrm{H} 0$ ditolak dan $\mathrm{H} 1$ diterima. Atau dapat dikatakan terdapat pengaruh yang signifikan antara Etika Kerja Islam dengan Kinerja Karyawan.

Tabel 1

Hasil Perhitungan Analisis Korelasi

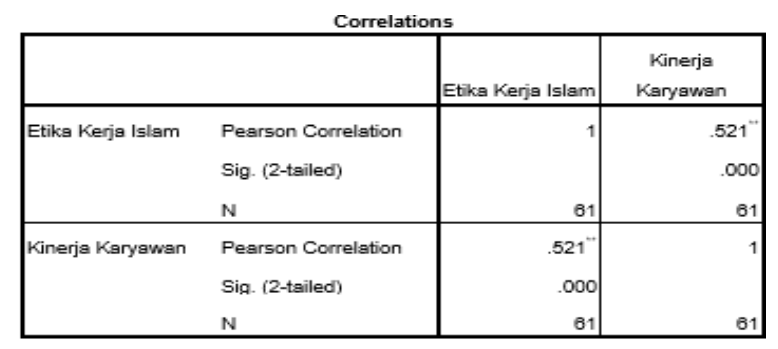

-. Correlation is significant at the 0.01 level (2-tailed).

Sumber : Hasil pengolahan data menggunakan SPSS 26.0, 2019
Berdasarkan hasil perhitungan analisis korelasi, dapat diketahui bahwa nilai koefisien korelasi antar kedua variabel sebesar 0,521 yang apabila diintrepretasikan dengan koefisien korelasi, skala 0,4 s.d. 0,59 menunjukkan hubungan yang sedang, berdasarkan hasil perhitungan analisis korelasi, maka angka 0,52 menunjukkan hubungan yang sedang antara variabel independen, yaitu Etika Kerja Islam dengan variabel dependen, yaitu Kinerja Karyawan.

\section{Analisis Regresi Linier Sederhana}

Analisis Regresi Linier Sederhana digunakan untuk mengetahui apakah variabel dependen (Y) dapat diprediksikan melalui variabel independen (X). Atau dengan istilah lain, teknik analisis ini adalah untuk mengetahui apakah naik turunnya variabel independen dapat memengaruhi kenaikan dan penurunan variabel dependen. Adapun untuk output koefisien regresi dapat dilihat pada Tabel 2.

Tabel 2

Analisis Regresi Linier Sederhana

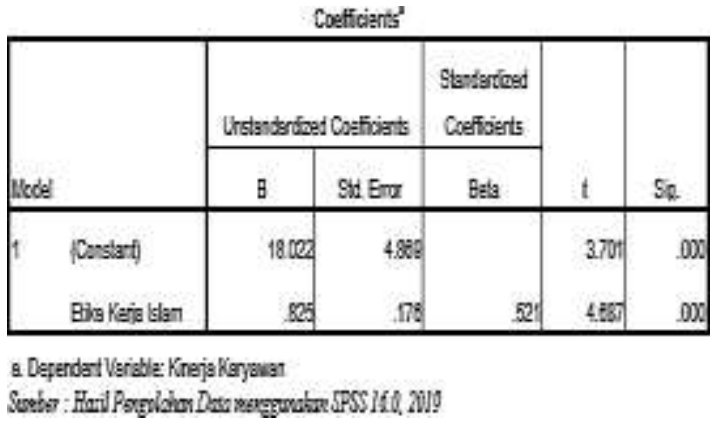

Berdasarkan hasil pengolahan data pada tabel 1.4 di atas, di dapatlah koefisien regresi $\mathrm{a}=18,022$, dan $\mathrm{b}=$ 0,825 . Dari nilai tersebut, maka persamaan regresi linier dalam penelitian ini adalah :

$$
\mathrm{Y}=18,022+0,825 \mathrm{X}
$$

Dari hasil persamaan di atas, dapat ditafsirkan bahwa koefisien regresi Kinerja karyawan adalah sebesar 0,825, 
artinya setiap terjadi kenaikan Etika Kerja Islam sebesar satu satuan, maka akan terjadi kenaikan/peningkatan pula pada Kinerja Karyawan sebesar 0,825. Kemudian, untuk menghitung besarnya pengaruh variabel Etika Kerja Islam terhadap kenaikan/penurunan Kinerja Karyawan dapat dihitung dengan mengggunakan rumus koefisien determinasi sebagai berikut :

$$
\begin{aligned}
\mathrm{KD} & =\mathrm{r} 2 \times 100 \% \\
& =(0,521) 2 \times 100 \% \\
= & 27,14 \%
\end{aligned}
$$

Hasil perhitungan di atas menunjukkan bahwa Etika Kerja Islam berpengaruh terhadap Kinerja Karyawan sebesar 27,14 $\%$, sedangkan sisanya yaitu sebesar 72,86 $\%$ dipengaruhi oleh faktor- faktor lain yang tidak diteliti oleh peneliti.

\section{Uji Hipotesis (Uji T)}

Pengujian hipotesis (dalam hal ini adalah uji T) digunakan untuk mengetahui tingkat signifikansi koefisien korelasi antara variabel independen dengan variabel dependen. Uji hipotesis digunakan untuk menguji korelasi antara satu variabel variabel independen dengan variabel dependen secara individu. Hasil nilai signifikansi diperoleh nilai signifikansi sebesar 0,00 (yaitu $<0,05$ ), sehingga dapat disimpulkan bahwa Variabel X , yaitu Etika Kerja Islam berpengaruh terhadap variabel Y, yaitu Kinerja Karyawan. Kemudian, diketahui nilai $\mathrm{t}$ hitung Etika Kerja Islam sebesar 4,687, dan $t$ tabel 2,001. Dapat diinterpretasikan bahwa variabel Etika Kerja Islam berpengaruh terhadap Kinerja

\section{KESIMPULAN DAN SARAN}

Etika Kerja Islam, berdasarkan hasil penelitian berada pada kategori sedang yang ditunjukkan dengan hasil perhitungan rata-rata index. Adapun untuk skor tertinggi pada Etika Kerja Islam terdapat pada dimensi Perceived Work as Worship, dan Cooperation. Hal ini menunjukkan bahwa karyawan departemen manufaktur PT. X telah memiliki kesadaran yang baik akan bekerja merupakan suatu ibadah

Dari hasil rekapitulasi data yang diperoleh, dapat diketahui bahwa hasil analisis deskriptif yang ditunjukkan dengan rata-rata index menunjukkan bahwa variabel Kinerja Karyawan berada dalam kategori sedang. Kemudian, ketiga dimensi yang dimiliki oleh Kinerja Karyawan, skor rata-rata tertinggi dimiliki oleh dimensi Adaptive Performance. Hal itu menandakan bahwa kemampuan karyawan dalam beradaptasi dengan berbagai macam perubahan di lingkungan pekerjaan sudah berada dalam kategori baik.

Kesimpulan akhir menyatakan bahwa Etika Kerja Islam berpengaruh positif dan signifikan terhadap Kinerja Karyawan. Berdasarkan hasil penelitian, peneliti merumuskan beberapa rekomendasi yang dapat dijadikan pertimbangan oleh PT. X agar dapat mengatasi permasalahan kinerja karyawan departemen manufaktur. Pada dimensi Etika Kerja Islam, dimensi terendah terdapat pada dimensi Effort dan Moral Responsible. Sesuai dengan hasil pengamatan peneliti selama melaksanakan penelitian di PT. X, terlihat bahwa dimensi Effort dan Moral Responsible pada karyawan Departemen Manufaktur menjadi dimensi yang paling rendah dibandingkan dengan dimensi lain.

Peneliti memberikan rekomendasi kepada korporasi berupa penyesuaian beban kerja dengan kompensasi yang diberikan, agar karyawan dapat merasakan keadilan dalam bekerja yang kelak dapat berimplikasi kepada produktivitas kerja dan meningkatnya tanggung jawab moral karyawan terhadap pekerjaan.

Kemudian pada dimensi Kinerja Karyawan, dimensi yang memiliki nilai terendah adalah dimensi Task Performance. Dimana untuk mengatasi permasalahan ini, perusahaan dapat memberikan kejelasan job description kepada para karyawannya dan 
memberikan semacam reward kepada karyawan yang upayanya sesuai dengan job description dan memberikan punishment kepada karyawan yang upayanya tidak sesuai dengan job description. Adapun secara lebih spesifik, indikator dengan hasil pengujian validitas terendah adalah tingkat kreativitas karyawan dalam bekerja. Hal tersebut dapat dicegah, salah satunya dengan mengadakan proses pelatihan dan pengembangan kepada karyawan departemen manufaktur agar setiap karyawan dapat terbiasa mengungkapkan ide-ide kreatifnya untuk kemajuan perusahaan, selain itu dengan memberikan kesempatan kepada setiap karyawan untuk mengemukakan pendapat dan gagasan terkait kemajuan perusahaan, tentu dapat menjadi solusi agar karyawan dapat mengeksplorasi ide-ide kreatifnya. Hal tersebut merupakan rekomendasi yang peneliti ajukan sesuai dengan hasil penelitian dan observasi selama di lapangan.

Peneliti merekomendasikan untuk penelitian selanjutnya agar dapat melaksanakan penelitian dengan mengkaji faktor-faktor lain yang mempengaruhi Kinerja Karyawan yang tidak peneliti sertakan dalam penelitian ini. Beberapa faktor tersebut diantaranya adalah kompensasi, pengembangan karir, dan lingkungan kerja fisik serta non-fisik. Beberapa faktor tersebut merupakan faktor-faktor yang peneliti rekomendasikan untuk diteliti di lingkungan karyawan Departemen Manufaktur PT. X sesuai dengan hasil observasi selama berada di lapangan.

\section{DAFTAR PUSTAKA}

Abdi, M.F., Muhamad Nor, S.F., \& Md Radzi, N.Z. (2014). The Impact of Islamic Work Ethics on Job Performance and Organizational Commitment. Proceedings of 5th Asia-Pacific Business Research Conference, Kuala Lumpur, Malaysia, 17-18 February 2014 (pp. 112). Melbourne, Victoria, Australia: World Business Institute Australia

Aldulaimi, Saeed. (2016). Fundamental Islamic Perspective of Work Ethics. Journal of Islamic Accounting and Business Research. $7 . \quad 59-76$. 10.1108/JIABR-02-2014-0006.

Ali, Abbas J. \& Owaihan, Abdullah. Islamic Work Ethic : A Critical Review. Cross Cultural Management : An International Journal. Vol. 15 No. 1 (Februari 2008), hlm. 5-18.

Ali, Abbas J. (2015). Handbook of Research on Islamic Business Ethic.United Kingdom : Edward Elgar Publishing

An-Nawawi. Matan Hadits Arba'in. Jakarta : Pustaka Ibnu 'Umar

Anonim. (2016). Human Resources Management. Mineapolis : Libraries Publishing

Armstrong, Michael. (2006). A Handbook of Human Resources Management Practice $10^{\text {th }}$ Edition. London : Kogan Page

Aziz, Farhan. (2018). Pengaruh Brand Personality terhadap Brand Emotional Bond pada Nasabah Tabungan Bank Muamalat di Kota Bandung. Skripsi. Universitas Pendidikan Indonesia Bandung

Bangun, Wilson. (2012). Manajemen Sumber Daya Manusia. Jakarta : Erlangga

Barling, Julian \& Cooper, Cary L. (2008). The SAGE Handbook of Organizational Behavior, Volume 1 : Micro Perspectives. Great Britain : Sage Publication

Bernadi, Beali. (2017). Pengaruh Knowledge Management terhadap Kinerja Karyawan (Studi Kasus pada Karyawan Produksi PT Dirgayusa Aparelindo). Skripsi. Universitas Pendidikan Indonesia Bandung

Chanzanagh, H.E. \& Akbarnejad, M. 
(2011). The Meaning and Dimensions of Islamic Work Ethic: Initial Validation of A Multidimensional IWE in Iranian Society. Procedia- Social and Behavioral Sciences, 30(178), 916924

Creswell, John W..(2017). Research Design (Pendekatan Metode Kualitatif, Kuantitatif, dan Campuran). Yogyakarta : Pustaka Pelajar

Djamilah, Siti. (2015). Pengembangan dan Validasi Ukuran Etika Kerja Islami dan Pengujiannya Pada Model Hubungan Etika Kerja Islami dengan Antisenden dan Konsekuensi Perilaku Kewargaan Organisasional. Disertasi. Universitas Gadjah Mada Yogyakarta

Desky, Harjoni. (2014). Pengaruh Etos Kerja Islami dan Gaya Kepemimpinan Terhadap Kinerja Karyawan. Vol. 8 No. 22014

Dessler, Gary. (2015). Manajemen Sumber Daya Manusia (Human Resources Management). Jakarta : Salemba Empat

Ferdinand, Augusty. (2014). Metode

Penelitian Manajemen. Semarang

: Badan Penerbit Universitas Diponegoro

Gunawan, Sandy. (2017). Pengaruh Insentif terhadap Kinerja Karyawan dengan Keadilan sebagai Variabel Moderasi pada PT. Lautan Teduh Interniaga. Skripsi. Universitas Lampung

Haroon, M \& Zaman, H.M.F. \& Rehman, Waiza. (2012). The Relationship Between Islamic Work Ethics and Job Satisfaction in Healthcare Sector of Pakistan. Int. J. Contemp. Bus. Stud.. 3. 6-12.

Hayati, Keumala \& Caniago, Indra. (2012). Islamic Work Ethic: The Role of Intrinsic Motivation, Job Satisfaction, Organizational Commitment and Job
Performance. Procedia - Social and Behavioral Sciences. 65. 272-277.

10.1016/j.sbspro.2012.11.122.

Hendrayadi. (2018). Islamic Work Ethics (IWE): Konsep dan Tinjauan Penelitian. Jurnal Riset Manajemen dan Bisnis (JRMB) Fakultas Ekonomi UNIAT, 3 (2), 183-190

Imam, Awais \& Abbasi, Abdus \& Muneer, Saima. (2018). Employee Performance from the Lens of Islamic Work Ethics Mediating Role of Personality $X$ and $Y$.

Jumalia, M. (2018). Pengaruh Budaya Kerja Dan Etos Kerja Islami Terhadap Kinerja Karyawan Pada Bank Syariah Mandiri Cabang Cirebon. Indonesian Journal of Strategic Management, 1(1).

Latham, Gary. (2007). The Oxford Handbook of Human ResourcesManagement. United States : Oxford University Press inc.

Marri, Muhammad \& Mahmood Sadozai, Arshad \& Fakhar Zaman, H.M. \& Ramay, M.I.. (2012). The impact of Islamic work ethics on job satisfaction and organizational commitment: a study of agriculture sector of Pakistan. 2. 32-45.

Mathis, Robert L. dan Jackson, John H.. (2008).Human Resources Management Twelfth Edition. United States of America: Thompson South Western

Scandura, Terri A. (2016). Essentials of Organizational Behavior, an Evidence-Based Approach. United States of America : SAGE Publications inc.

Shukri Ahmad, dkk. The Concept of Islamic Work Ethic : An Analysis of Some Salient Points in The Prophetic Tradition. International Journal of Business and Social Science. Vol. 3 No. 20 (Oktober 2012). hlm. 118. 
Sonnentag, S. and Frese, M. (2002).

Performance concepts and

performance theory, in S.

Sonnentag (ed.), Psychological

Management of Individual

Performance. Chichester: Wiley,

pp. 3-25

Suib, Husan Fatin, Said, Mohd. Fuaad. (2017). A Review of Islamic Work Ethics and Spirituality Concepts in Service Industry: Journal of Nusantara Studies. Vol. 2 (2) 282294

Sulistiyani, Ambar Teguh dan Rosidah (2018). Manajemen Sumber Daya Manusia. Yogyakarta : Gava Media

Sugiyono. (2014). Metode Penelitian Kuantitatif, Kualitatif, dan Kombinasi (Mixed Methods). Bandung: Alfabeta.

Sugiyono. (2018). Metode Penelitian Kuantitatif, Kualitatif, dan $R \& D$. Bandung: Alfabeta.

Suharsimi, A. (2010). Prosedur Penelitian Suatu Pendekatan Praktik. Jakarta: Rineka Cipta.

Suib, Husna Fatin dan Said Mohd. Fuaad. (2017). A Review of Islamic Work Ethics and Spirituality Concepts in Service Industry. Journal of Nusantara Studies, Vol. 2 (2) 282294 